\title{
Total Cost of Ownership of electric vehicles using energy from a renewable-based microgrid
}

\author{
Alessandro Massi Pavan, Vanni Lughi \\ Department of Engineering and Architecture \\ University of Trieste, Italy \\ apavan@units.it
}

\author{
Mariangela Scorrano \\ Department of Economics, Business, \\ Mathematics and Statistics \\ University of Trieste, Italy \\ mscorrano@units.it
}

\begin{abstract}
This work aims at analyzing the integration between electric mobility and renewable energy sources studying the case of the grid-connected microgrid under construction at the University of Trieste, Italy. A general model able to estimate the charging price and the resulting total cost of ownership per kilometer considering the match between the demand and the production of a photovoltaic generator is presented. The result is that the electric vehicle is mainly charged with the produced renewable energy $(72 \%)$ and that the $60 \%$ of it flows through the storage unit. The study also presents a sensitivity analysis to show how the battery size and cost, together with the travelled distance, influence the charging price and the total cost of ownership per kilometer. Considering the current Italian prices and subsidies, results show that the use of an electric car is today feasible from both an environmental and an economic point of view.
\end{abstract}

Index Terms--Electric Vehicles, LCOE, LCOS, microgrid, TCO.

\section{INTRODUCTION}

Concerns with global warming, oil shortages and rising gas prices are gradually impacting automotive industries, that so far have relied on fossil fuels and caused a significant part of polluting emissions. The electrification of the transportation sector and in particular the usage of Electric Vehicles (EVs) is becoming ever more attractive, affecting consumers' choices $[1,2]$. However, the strict European targets set for the reduction of greenhouse gas emissions, the required improvement of system's security and reliability, and the increasing share of intermittent renewable energy sources are calling for important changes in our energy systems. Beyond uncontested environmental benefits, in fact, the rollout of electric vehicles poses challenges to power systems, starting from the additional power demand for recharging their batteries, possibly overlapping with the system peak demand $[3,4]$. Power system operators, therefore, have to face a twofold challenge: managing the adequacy of the grid capacity and

Authors gratefully acknowledge for the financial support provided by "MUSE - Cross-border collaboration for a sustainable and energetically efficient university mobility", a project cofinanced by the European Regional Development Fund via the cross-border cooperation program Interreg Italy-Slovenia. integrating electric vehicles into the power system, in a context of increasingly volatile supply due to a growing share of renewable energy sources. Among these, solar and wind energy play a significant role. Photovoltaics is growing exponentially worldwide since many years and with $400 \mathrm{GW}_{\mathrm{p}}$ [5] installed represents one of the most important realities in the sector of the distributed generation. An increasing number of residential and commercial/industrial buildings hosting PV plants produce electricity that can be directly consumed or, in case of excess of production, fed into the grid or stored in an energy storage device. The use of storage units has the additional benefit of mitigating the challenges posed by intermittent power generation and mismatching of energy supply and demand. In combination with energy storage, intelligent load management may lead to sensible improvements in the energy self-consumption in buildings [6]. This is desirable not only because it provides flexibility to the power operator and increases the reliability of the renewable energy sources, but also from an economic standpoint.

Electric vehicles, if charged using charging stations integrated in the electric systems of buildings, can be considered as dynamical storage systems [7]. This leads to a potential synergy between mobility and power systems and the problem becomes the solution as the challenge of the increased electric power demand associated to the growing electric mobility is mitigated by the electric vehicles themselves. In this scenario, through an efficient management of electric vehicles charging demand, the electricity costs can be lowered, thus reducing the operating costs of the vehicle and, consequently, the Total Cost of Ownership per kilometer (TCO/km). Thus, EVs competitiveness can be strengthened, contributing to their uptake.

In this work, we analyze the integration between mobility and renewable energy sources in a real environment. The object of the study is a grid-connected microgrid consisting of a PV system installed on the rooftop of a university building (University of Trieste, Italy), an energy storage system, and a charging station for EVs. We analyze the economic viability of charging an EV using the microgrid and considering the travel behavior of different users. We compare the drivers' 
recharging time profile with the daily PV production profile. In this way, we are able to compute the fraction of the energy used for recharging the EVs obtained from the public grid and that from the PV system (directly or indirectly using the storage unit), thus enabling an estimation of the $\mathrm{TCO} / \mathrm{km}$ for the EVs compared to that of an equivalent petrol car. We then propose a sensitivity analysis in order to verify the relevant parameters for the EVs to be cost competitive or even cheaper than the equivalent petrol car in terms of TCO $/ \mathrm{km}$.

The paper is organized as follows: the next Section describes the microgrid under construction at the University of Trieste, while Section III is on the calculation of the PV Levelized Cost of Energy (LCOE) and Levelized Cost of Storage (LCOS). Section IV describes the model used to determine the EV load profile, and the calculation of the $\mathrm{TCO} / \mathrm{km}$ for two representative vehicles is presented in Section $\mathrm{V}$. The conclusions of the work are given in Section VI.

\section{THE MiCROGRID OF THE UNIVERSITY OF TRIESTE}

The assumptions used in this work are based on the microgrid financed by "MUSE - Cross-border collaboration for a sustainable and energetically efficient university mobility", a project cofinanced by the European Regional Development Fund via the cross-border cooperation program Interreg Italy-Slovenia.

With reference to Fig. 1, the microgrid that is under construction at the University of Trieste consists of a $3.9 \mathrm{~kW}_{\mathrm{p}}$ photovoltaic generator, a $4.6 \mathrm{kVA}$ inverter, a $10 \mathrm{kWh}$ lithium iron phosphate battery, an interface board (IB) performing the connection with the low voltage (LV) $230 \mathrm{~V}$ grid, and a 22 plus $22 \mathrm{~kW}$ charging station. An Energy Management System (EMS) optimizes the energy flows between the different parts of the microgrid where the data are exchanged through the Campus LAN. The EMS can take as an input some external references such as, for example, the meteorological forecast or the electricity price. Finally, the main parameters of the plant will be shown in real-time using an outdoor 55 " display.

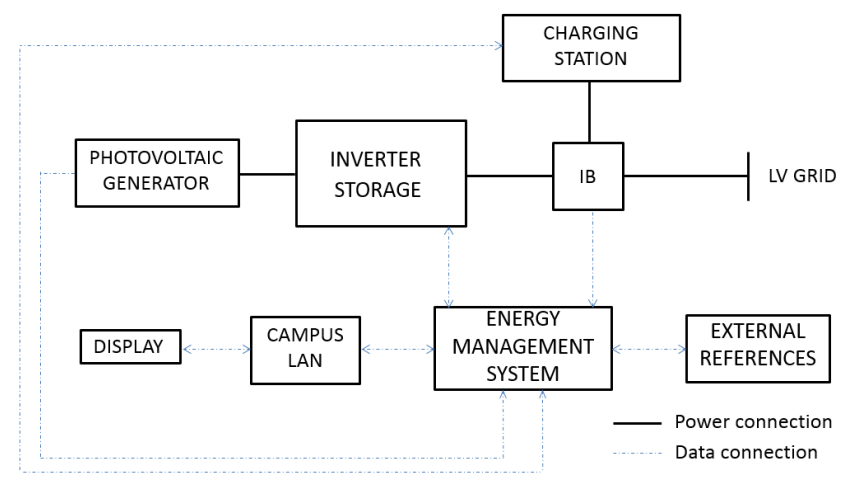

Figure 1: The microgrid under construction at the University of Trieste, Italy

\section{EV CHARGING COSTS}

The cost of the energy used to charge an electric vehicle, $E_{\text {price}}$, depends on the source of electricity. When this comes directly from the PV system, the cost of the kilowatt-hour corresponds to the LCOE of the solar generator. If the kilowatt- hour comes from the storage system, and if this energy was produced by the PV generator, then its cost is the LCOE plus the LCOS. In the case of a direct charge from the grid, the kilowatt-hour cost corresponds to the electricity price, $E_{\text {grid, }}$, that the University pays to the local Distribution System Operator. In this study, we do not consider the case when the storage is charged with the energy coming from the grid. Thus, the charging cost can be expressed as:

$$
E_{\text {price }}=\alpha \cdot L C O E+\beta \cdot(L C O E+L C O S)+\gamma \cdot E_{\text {grid }}
$$

where $\alpha, \beta$ and $\gamma$ are the amounts of energy (in $\%$ of the total need) from the different sources.

\section{A. The Levelized Cost of Energy}

The cost of the energy produced by a photovoltaic plant is given by [8]:

$$
L C O E=\frac{O C S \cdot C R F+F O \& M C}{\frac{E_{0}}{N} \cdot \sum_{k=1}^{N}\left(1-\frac{d_{r}(k-1)}{100}\right)}
$$

where OCS is the Overnight Capital Cost of the PV plant, $C R F$ the Capital Recovery Factor, FO\&MC are the Fixed Operation and Maintenance Costs, $E_{0}$ is the yield of the plant during the first year of operations, $N$ is the life span of the system, and $d_{r}$ is the degradation rate of the PV modules. In this study, the $O C S$ has been set to $1,500.00 € / \mathrm{kW}_{\mathrm{p}}, F O \& M C$ are the $2.5 \%$ of the initial cost, $E_{0}$ is $1,235 \mathrm{kWh} / \mathrm{kW}_{\mathrm{p}} /$ year [9], $N$ is 30 years, and $\mathrm{d}_{\mathrm{r}}$ is $0.6 \%$ /year [10]. CRF is $5.6 \%$ considering a cost of money of $3.7 \%$ that corresponds to the actual yield on Italian government bonds with a 30-year maturity [11]. The LCOE for the considered PV plant is then $0.076 € / \mathrm{kWh}$.

\section{B. The Levelized Cost of Storage}

The cost of the energy stored in the battery can be calculated as [12]:

$$
L C O S=\frac{I_{0}+\sum_{i=1}^{n} \frac{F O \& M C_{i}}{(1+w a c c)^{i}}}{\sum_{i=1}^{n} \frac{E_{i}}{(1+w a c c)^{i}}}
$$

where $I_{0}$ is the battery upfront cost, $F O \& M C_{i}$ are the annual operation and maintenance costs during year $i$, wacc is the weighted average cost of money, and $E_{i}$ is the energy exchanged with the battery in the year $i$.

In this study, the cost of the battery is $400.00 € / \mathrm{kWh}$, the operation and maintenance costs are zero as the microgrid is equipped with maintenance-free batteries. The cost of money is also set to zero as this does not affect the value of the energy exchanged with the battery (this is charged using the energy produced by the PV plants only). With these assumptions, the LCOS for the considered application is $0.094 € / \mathrm{kWh}$.

\section{ElECTRIC VeHICLE LOAD PROFILE}

For the determination of the electric vehicle load profile, potential driving patterns are influenced by many factors such as the covered distance, the driving style as the speed and the 
fuel consumption, the initial state of charge, etc. For the uncertain nature of the variables characterizing the charging schedule, Monte Carlo simulations are often used. The microgrid under construction at the University of Trieste will be preliminary tested using one electric vehicle that will be at employees' disposal. Hence, in this study, we simulate the movements of this EV during the 365 days of the year, detecting the time at which the charging becomes necessary together with the requested amount of energy. For a due day, the charging time occurs when the vehicle is parked and connected to the University charging station. The State of Charge (SoC) of the vehicle's battery at the arrival time, $S o C_{a r r}$, depends on the charging level at the departure, $S o C_{d e p}$, the covered distance $D$, the average consumption $C$, and the total battery capacity $B C[13]$ :

$$
S o C_{a r r}=S o C_{d e p}-D \cdot C \cdot \frac{100}{B C}
$$

If the arrival state of charge is lower or equal to a fixed threshold level, $S o C_{\text {thres }}$, then the EV has to be charged during the trip. In this case, the time when the recharge starts is equal to:

$$
t_{C S}=t_{d e p}+\frac{D_{C S}}{v}
$$

where $t_{d e p}$ is the departure time, $v$ is the average speed of the vehicle, and $D_{C S}$ is the distance between the departure place to the charging point.

Setting the maximum state of charge of the battery to $80 \%$ (for the sake of time saving), the amount of energy fed into the EV battery is:

$$
E_{C S}=\left(\frac{80-S o C_{\text {thres }}}{100}\right) \cdot B C
$$

The arrival time at the destination (the University campus) can be calculated as:

$$
t_{\text {arr }}=t_{C S}+\Delta t_{C S}+t_{w o r k}+\frac{\left(D-D_{C S}\right)}{v}
$$

where $\Delta t_{C S}=\frac{E_{C S}}{P_{C S}}$ is the duration of the charge, $P_{C S}$ is the charging power, and $t_{\text {work }}$ is the time the driver spends for out of office working purposes.

The amount of energy from the microgrid can be calculated as:

$$
E_{\text {micro-grid }}=0.8 \cdot B C-\left(D-D_{C S}\right) \cdot C
$$

If short distances are travelled and the battery's departure state of charge is enough for the entire trip, the above equations simplify. The arrival time at the destination becomes:

$$
t_{\text {arr }}=t_{d e p}+\frac{D}{v}
$$

and the amount of energy required from the microgrid is simply the discharged energy, equal to:

$$
E_{\text {microgrid }}=D \cdot C
$$

The electric vehicle used in the MUSE project is a Nissan Leaf with an average consumption of $0.17 \mathrm{kWh} / \mathrm{km}$, and a battery capacity of $40 \mathrm{kWh}$. Users are the University employees who use the EV only for working tasks. We suppose that the drivers always start the trip with a fully charged car and that they charge when the battery reaches the $20 \%$ of the departure state of charge. Different drivers' behaviors have been simulated considering stochastic probability distributions for the main parameters of the model. In particular, the departure time, the distance covered, and the parking time have been extracted from a normal distribution. The average departure time is 10.00 a.m. with a standard deviation of 2 hours and assuming the user leaves the University building within the range [8.00 a.m. -2.00 p.m.] The daily average distance is $60 \mathrm{~km}$ (up to $100 \mathrm{~km}$ ) with a standard deviation of $10 \mathrm{~km}$. The average speed is $70 \mathrm{~km} / \mathrm{h}$, and the average parking time is 2 hours with a standard deviation of one hour. The simulations, performed for 365 days in a year, gave as a result a total distance of $18,000 \mathrm{~km}$ corresponding to an annual energy demand of 3,524 $\mathrm{kWh}$.

\section{THE TOTAL COST OF OWNERSHIP}

The Total Cost of Ownership is a useful indicator to determine the direct and indirect costs of buying and owning a vehicle. An extensive literature $[14,15]$ studies the importance of both monetary (e.g. purchase price, taxes, operating costs, parking fees, etc.) and non-monetary (e.g. driving range, brand, charging time, presence of charging infrastructures, the size and the car market segment, etc.) factors. As the monetary variables play the most important role, this study focuses only on financial costs and compute the TCOs of two cars with different propulsion systems. In the comparison between electric and endothermic cars, the former are characterized by higher initial costs, that are immediately perceivable, and lower operating costs, that on the contrary are more difficult to assess. TCO models help to increase consumers' awareness by properly identifying and computing the numerous cost components. Also, car manufacturers use TCO models in order to predict future cars trends or to market their products more effectively. The ratio between the TCO and the travelled kilometer is [1]:

$$
\frac{T C O}{k m}=\frac{(I C+I G-R V * P V F) * C R F+\frac{1}{T} \sum_{t=1}^{T} \frac{A O C_{t}}{(1+i)^{t}}}{A K T}
$$

where $I C$ includes the upfront cost of the vehicle (including the Manufacturer's Suggested Retail Price MSRP, the Registration Costs $R C$, and the Government Subsidies GS [16]). $I G$ accounts for the earnings due to the interest payments, $R V$ and $P V F$ are the residual and the present value of the vehicle respectively. $A K T$ is the distance covered by the car in one year, $A O C$ are the annual operating costs (including Insurance Premium $I P$, Car Tax $C T$ [16], maintenance costs, Fuel Cost $F C$, etc.), and $T$ is the number of years the owner keeps the car. The electric car used in the MUSE project is a 
Nissan Leaf and its performance is compared with the one of the petrol equivalent Nissan Pulsar. Table I lists the main cost parameters (that come from a market survey made in the area of Trieste, Italy) for the two cars and the resulting TCOs $/ \mathrm{km}$. The $C R F$ has been calculated considering an interest rate of $6 \%$ and an ownership period of six years.

TABLE I. MAIN COST PARAMETERS

\begin{tabular}{|c|c|c|}
\hline & NISSAN LEAF & NISSAN PULSAR \\
\hline MSRP & $€ 36,360.00$ & $€ 23,640.00$ \\
\hline RC & $€ 375.00$ & $€ 501.00$ \\
\hline GS & $€ 5,000.00$ & $€ 0.00$ \\
\hline CRF & 0.2 & 0.2 \\
\hline AKT & $18,000 \mathrm{~km}$ & $18,000 \mathrm{~km}$ \\
\hline IP & $€ 285.00$ & $€ 421.00$ \\
\hline $\mathbf{C T}$ & $€ 0.00$ & $€ 150.00$ \\
\hline $\mathbf{F C}$ & $0.166 € / \mathrm{kWh}$ & $1.642 € / 1$ \\
\hline $\mathbf{T C O} / \mathbf{k m}$ & $€ 0.34$ & $€ 0.35$ \\
\hline
\end{tabular}

\section{A. Base Case Scenario}

With reference to the electric vehicle, the charging cost has been calculated using (1), where $L C O E$ was $0.076 € / \mathrm{kWh}$, $\operatorname{LCOS} 0.094 € / \mathrm{kWh}$, and the electricity price is $0.197 € / \mathrm{kWh}$ (corresponding to the 2018 CONSIP price reserved to the public administrations in the considered area [17]). The weights $\alpha, \beta$ and $\gamma$ have been calculated comparing the PV production profile with the load profile of the electric vehicle as determined using the method explained in Section III. For the generation, the real production profile of the gridconnected PV plant installed on the rooftop of a building inside the main University of Trieste Campus [18] has been used, as this is located in the same location where the microgrid will operate. The dataset provides the average powers, with a sample time of ten minutes, measured during the period June $30^{\text {th }} 2008-$ June $29^{\text {th }} 2009$. The energy management system ensures that the PV production is directly used to charge the $\mathrm{EV}$ when this is available at the charging station. When the PV production exceeds the load needs or, when the EV is not available, the PV energy is stored in the storage unit of the microgrid. Moreover, if the EV is not available and the battery is already fully charged, then the PV energy is fed into the local grid. Finally, if the PV generator is not available and the SoC of the battery is zero, then the EV is charged using the energy from the grid.
TABLE II. PV ENERGY FLOWS

\begin{tabular}{|l|c|c|c|}
\hline & PV2EV & PV2ST & PV2Grid \\
\hline Energy $[\mathbf{k W h}]$ & 422 & 2,132 & 2,463 \\
\hline \% of E EV & 8 & 43 & 49 \\
\hline
\end{tabular}

TABLE III. CHARGING ENERGY FLOWS

\begin{tabular}{|l|c|c|c|}
\hline & PV2EV & ST2EV & Grid2EV \\
\hline Energy $[\mathbf{k W h}]$ & 422 & 2,132 & 971 \\
\hline \% of Echarg & $\alpha=12$ & $\beta=60$ & $\gamma=28$ \\
\hline
\end{tabular}

Table II shows the data regarding the PV energy flows in one year where the total PV production $E_{P V}$ is $5,017 \mathrm{kWh}$. $P V 2 E V$ is the energy flow from the PV plant to the EV, PV2ST is the one from the PV generator to the storage, and PV2grid is the energy fed into the grid. Table III lists the charging energy flows together with the calculated weights $\alpha, \beta$ and $\gamma$ where the total charging energy $E_{\text {charg }}$ is $3,524 \mathrm{kWh}$. ST2EV is the energy flow from the storage to the EV, and Grid2EV is the one from the grid to the EV. Table II reveals that more than half (51\%) of the energy produced by the PV generator goes into the electric vehicle. Table III indicates that the $72 \%$ of the energy used to charge the car is from the solar generation and thus renewable. Using the weights $\alpha, \beta$ and $\gamma$ we calculate a charging price of $0.166 € / \mathrm{kWh}$ that is lower than the cost of one kilowatt-hour from the grid (equal to 19.7 eurocent). This results in the $\mathrm{TCO} / \mathrm{km}$ for the EV that, according to Table I, is lower than that of the endothermic vehicle.

\section{B. Sensitivity Analysis}

In this Section, we present the results of the sensitivity analysis developed in order to understand how the cost and the size of the battery affect the cost of the charging energy and of the $\mathrm{TCO} / \mathrm{km}$. Moreover, we also present the results where the annual travelled distance is varied.

With reference to Table IV, the green cells indicate the cases when the charging energy costs are lower than the price of the electricity from the grid. We notice that the cost of the charged energy is always lower than the one from the grid unless the size of the battery is greater than $10 \mathrm{kWh}$. This happens also when the price of the battery is $150 € / \mathrm{kWh}$. The table also contains the information regarding the optimal size of the battery for a fixed battery price. For example, for a price of $400 € / \mathrm{kWh}$ the optimal sizes are 1 and $5 \mathrm{kWh}$. 
TABLE IV. Price OF THE ChARGED ENERGY [ $€ / \mathrm{KWH}]$

\begin{tabular}{|c|c|c|c|c|c|c|c|c|c|}
\hline & \multicolumn{8}{|c|}{ Battery Price $[€ / \mathbf{k W h}]$} \\
\hline & & 150 & 200 & 250 & 300 & 350 & 400 & 450 & 500 \\
\hline \multirow{9}{*}{ 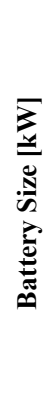 } & 1 & 0.16 & 0.16 & 0.16 & 0.16 & 0.16 & 0.16 & 0.16 & 0.16 \\
\hline & 5 & 0.14 & 0.15 & 0.15 & 0.15 & 0.16 & 0.16 & 0.16 & 0.17 \\
\hline & 10 & 0.13 & 0.14 & 0.14 & 0.15 & 0.16 & 0.17 & 0.17 & 0.18 \\
\hline & 15 & 0.13 & 0.14 & 0.15 & 0.16 & 0.17 & 0.18 & 0.19 & 0.20 \\
\hline & 20 & 0.14 & 0.15 & 0.17 & 0.18 & 0.19 & 0.21 & 0.22 & 0.24 \\
\hline & 25 & 0.14 & 0.16 & 0.18 & 0.20 & 0.22 & 0.23 & 0.25 & 0.27 \\
\hline & 30 & 0.15 & 0.17 & 0.20 & 0.22 & 0.24 & 0.26 & 0.28 & 0.30 \\
\hline & 35 & 0.16 & 0.19 & 0.21 & 0.24 & 0.26 & 0.29 & 0.31 & 0.33 \\
\hline & 40 & 0.17 & 0.20 & 0.23 & 0.26 & 0.28 & 0.31 & 0.34 & 0.37 \\
\hline
\end{tabular}

TABLE V. TCO/KM [€]

\begin{tabular}{|c|c|c|c|c|c|c|c|c|c|}
\hline & \multicolumn{8}{|c|}{ Battery Price $[€ / \mathbf{k W h}]$} \\
\hline & & 150 & 200 & 250 & 300 & 350 & 400 & 450 & 500 \\
\hline \multirow{9}{*}{ 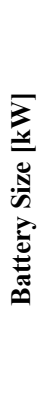 } & 1 & 0.34 & 0.34 & 0.34 & 0.34 & 0.34 & 0.34 & 0.34 & 0.34 \\
\hline & 5 & 0.34 & 0.34 & 0.34 & 0.34 & 0.34 & 0.34 & 0.34 & 0.34 \\
\hline & 10 & 0.33 & 0.34 & 0.34 & 0.34 & 0.34 & 0.34 & 0.34 & 0.34 \\
\hline & 15 & 0.33 & 0.34 & 0.34 & 0.34 & 0.34 & 0.34 & 0.35 & 0.35 \\
\hline & 20 & 0.33 & 0.34 & 0.34 & 0.34 & 0.35 & 0.35 & 0.35 & 0.35 \\
\hline & 25 & 0.34 & 034 & 0.34 & 0.35 & 0.35 & 0.35 & 0.36 & 0.36 \\
\hline & 30 & 0.34 & 0.34 & 0.35 & 0.35 & 0.35 & 0.36 & 0.36 & 0.37 \\
\hline & 35 & 0.34 & 0.34 & 0.35 & 0.35 & 0.36 & 0.36 & 0.37 & 0.37 \\
\hline & 40 & 0.34 & 0.34 & 0.35 & 0.36 & 0.36 & 0.37 & 0.37 & 0.38 \\
\hline
\end{tabular}

In Table $\mathrm{V}$ the green cells show the cases when the $\mathrm{TCO} / \mathrm{km}$ of the $\mathrm{EV}$ is lower than the one of the endothermic car. It can be noticed that the $\mathrm{TCO} / \mathrm{km}$ for the $\mathrm{EV}$ is always cost competitive with respect to the petrol equivalent car when the cost of the battery is lower than $250 € / \mathrm{kWh}$ or if the size of the battery is not greater than $10 \mathrm{kWh}$.

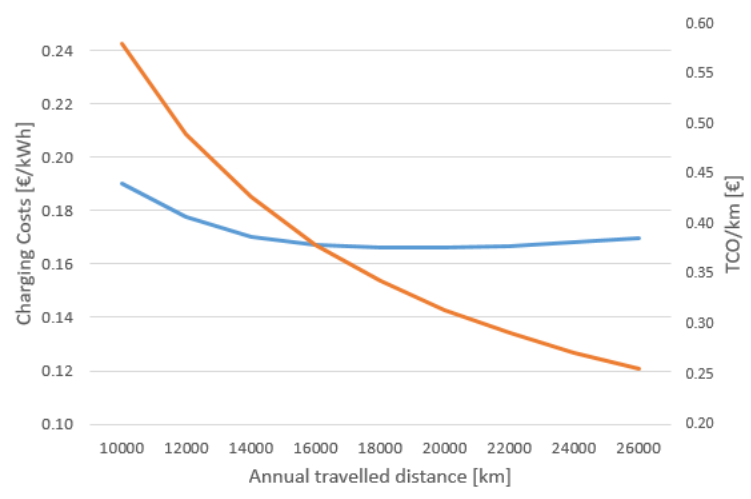

Figure 2: Dependance of the charging costs and of the TCO/ $\mathrm{km}$ from the travelled distance

The results of the second sensitivity analysis are shown in Fig. 2 where the minimum charging costs are achieved for a distance greater than $14,000 \mathrm{~km}$. Fig. 2 also indicates that the travelled distance greatly affects the $\mathrm{TCO} / \mathrm{km}$ and, also, that this is lower than petrol equivalent $(\mathrm{TCO} / \mathrm{km}=€ 0.35)$ when the distance is greater than $18,000 \mathrm{~km}$.

\section{CONCLUSIONS}

The paper proposes a model to estimate the Total Cost of Ownership per kilometer of an electric vehicle that is charged with the energy produced by a grid-connected PV based microgrid. The energy load due to the use of the electric vehicle has been calculated using a model accounting for the departure time, the distance travelled, and the charging time. The match between the load profile and the PV generation together with the management of the energy flows allow the calculation of the charging costs and of the $\mathrm{TCO} / \mathrm{km}$.

The model is applied to the microgrid set up at the University of Trieste, consisting of a $3.9 \mathrm{~kW}_{\mathrm{p}}$ PV generator, a $10 \mathrm{kWh}$ storage battery, and a Nissan Leaf electric car. When the car is driven at least $18,000 \mathrm{~km}$ per year, we found that the $\mathrm{EV}$ is mainly charged with the energy coming from the PV system $(72 \%)$ and that this was made possible especially because of the storage unit within the microgrid that manages the $60 \%$ of the total PV generation.

The PV Levelized Cost of Energy (LCOE) and the Levelized Cost of Storage (LCOS) are 0.076 and $0.094 € / \mathrm{kWh}$ respectively, the electricity price is $0.197 € / \mathrm{kWh}$, and the resulting charging cost is $0.166 € / \mathrm{kWh}$. This is an interesting result as the use of a storage unit embedded in the microgrid allows the use of a quite high percentage of renewable energy at a cost that is lower than the price of electricity from the grid.

Moreover, the study shows that, for the base case scenario, the obtained $\mathrm{TCO} / \mathrm{km}$ of the electric car is better than the one of the petrol equivalent Nissan Pulsar.

Finally, we simulated the changes in the cost of energy and of the $\mathrm{TCO} / \mathrm{km}$ varying the storage battery price and size, and we also presented the optimal size of the battery as a function of the battery price.

In conclusion, with the current Italian prices, including the recent national and regional EV subsidies, the use of an electric car is convenient both from an economic and an environmental point of view. In this study we did not consider any subsidy for the installation of the PV generator and the storage unit that might accelerate microgrid-supported EV adoption.

Further research topics might be on the investigation of the optimal size of the PV generator and storage unit as a function of the number of cars, the use of a mixed fleet of EVs including staff and students, and a cost/benefit analysis of the investment for the microgrid and its payback time period.

\section{REFERENCES}

[1] R. Danielis, M. Giansoldati, and L. Rotaris, "A probabilistic total cost of ownership model to evaluate the current and future prospects of electric cars uptake in Italy", Energy Policy, vol. 119, pp. 268-281, 2018.

[2] M. Giansoldati, R. Danielis, L. Rotaris, and M. Scorrano, "The role of driving range in consumers' purchasing decision for electric cars in Italy", Energy, vol. 155, pp. 267-274, 2018.

[3] H. Liang, Y. Liu, F. Li, and Y. Shen, "Dynamic economic/emission dispatch including PEVs for peak shaving and valley filling", IEEE Transaction on Industrial Electronics, vol. 66, pp. 2882-2890, 2019.

[4] M. Brenna, A. Dolara, F. Foiadelli, S. Leva, and M. Longo, "Urban scale photovoltaic charging stations for electric vehicles", IEEE Transaction on Sustainable Energy, vol. 5, pp. 1234-1241, 2014. 
[5] "Snapshot of global photovoltaic market", Photovoltaic Power Systems Programme, Report IEA T1-33:2018.

[6] L. Martirano, E. Habib, G. Parise, G. Greco, M. Manganelli, F. Massarella, and L. Parise, "demand side management in microgrids for load control in nearly zero energy buildings", IEEE Transaction on Industry Applications, vol. 53, pp. 1769-1779, 2017.

[7] K. N. Kumar, B. Sivaneasan, P. H. Cheah, P. L. So, and D. Z. Wang, "V2G capacity estimation using dynamic EV scheduling", IEEE Transaction on Smart Grid, vol. 5, pp. 1051-1060, 2014.

[8] A. Massi Pavan, and V. Lughi, "Photovoltaics in Italy: towards grid parity in the residential electricity market". In Proc. of 2012 IEEE International Conference on Microelectronics, pp. 1-4.

[9] F. Pauli, G. Sulligoi, V. Lughi, and A. Massi Pavan, "Grid parity in the Italian domestic PV market: a sensitivity analysis". In Proc. of 2015 IEEE International Conferemce on Renewable Energy Research and Applications, pp. 1477-1480.

[10] https://www.qcells.com/au/main/products/solar_modules/residential/residential02.ht ml [accessed December 2018].

[11] http://www.dt.tesoro.it/it/debito pubblico/emissioni titoli di stato int erni/risultati_aste/risultati_aste btp_30 anni/index.html [accessed December 2018].

[12] "E-storage: shifting from cost to value. Windand solar applications", World Energy Council Report, 2016.
[13] G. Celli, G. Soma, F. Pilo, F. Lacu, S. Mocci, and N. Natale, "Aggregated electric vehicles load profiles with fast charging stations". In Proc. of 2014 IEEE Power Systems Computation Conference, pp. 17.

[14] M. E. Biresselioglu, M. D. Kaplan, and B. K. Yilmaz, "Electric mobility in Europe: A comprehensive review of motivators and barriers in decision making processes", Transportation Research Part A: Policy and Practice, vol. 109, pp. 1-13, 2018.

[15] M. Coffman, P. Bernstein, and S. Wee, "Electric vehicles revisited: a review of factors that affect adoption", Transport Reviews, vol. 37, pp. 79-93, 2017.

[16] Friuli Venezia Giulia Regional Law N. 45/2017.

[17] http://www.consip.it/media/news-e-comunicati/consip-aggiudicata-la15 esima-edizione-della-gara-per-energia-elettrica-alle-pa [accessed December 2018].

[18] A. Massi Pavan, S. Castellan, S. Quaia, S. Roitti, and G. Sulligoi, "Power electronic conditioning systems for industrial photovoltaic fields: centralized or string inverters?". In Proc. 2007 IEEE Interantional Conference on Clean Electrical Power, pp. 208-214. 